\title{
Overstimulated Consumers or Next-Generation Learners? Parent Tensions About Child Mobile Technology Use
}

\author{
Jenny S. Radesky, $M D^{1}$ \\ Staci Eisenberg, $M D^{2}$ \\ Caroline J. Kistin, MD, MSc ${ }^{3}$ \\ Jamie Gross, $B A^{3}$ \\ Gabrielle Block, BS \\ Barry Zuckerman, $M D^{3}$ \\ Michael Silverstein, $M D, M P H^{3}$ \\ 'Division of Developmental Behavioral \\ Pediatrics, Department of Pediatrics, Uni- \\ versity of Michigan, Ann Arbor, Michigan \\ ${ }^{2}$ Division of Medicine-Pediatrics, Brown \\ University School of Medicine, Providence, \\ Rhode Island \\ ${ }^{3}$ Division of General Academic Pediat- \\ rics, Department of Pediatrics, Boston \\ University School of Medicine, Boston, \\ Massachusetts
}

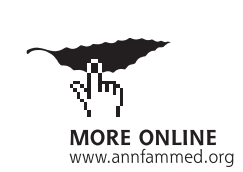

Conflicts of interest: authors report none.

\section{CORRESPONDING AUTHOR}

Jenny S. Radesky, MD

Division of Developmental Behavioral

Pediatrics

Department of Pediatrics

University of Michigan

$300 \mathrm{~N}$ Ingalls St

Ann Arbor, MI 48108

jradesky@umich.edu.

\begin{abstract}
PURPOSE Mobile technology is ubiquitous, but its impact on family life has not been thoroughly addressed in the scientific literature or in clinical practice guidelines. We aimed to understand parents' views regarding mobile technology use by young children, aged 0 to 8 years, including perceived benefits, concerns, and effects on family interactions, with the goal of informing pediatric guidelines.
\end{abstract}

METHODS We conducted 35 in-depth, semistructured group and individual interviews with English-speaking caregivers of diverse ethnic backgrounds, educational levels, and employment statuses. After thematic saturation, results were validated through expert triangulation and member checking.

RESULTS Participants included 22 mothers, 9 fathers, and 4 grandmothers; $31.4 \%$ were single parents, $42.9 \%$ were of nonwhite race or ethnicity, and $40.0 \%$ completed high school or less. Participants consistently expressed a high degree of tension regarding their child's mobile technology use, from which several themes emerged: (1) effects on the child-fear of missing out on educational benefits vs concerns about negative effects on thinking and imagination; (2) locus of control-wanting to use digital devices in beneficial ways vs feeling that rapidly evolving technologies are beyond their control (a tension more common in low-income caregivers); and (3) family stress-the necessity of device use in stressed families (eg, to control a child's behavior or as an inexpensive learning/ entertainment tool) vs its displacement of family time.

CONCLUSIONS Caregivers of young children describe many novel concepts regarding use of mobile technology, raising issues not addressed by current anticipatory guidance. Guidance may be more effectively implemented if it takes into account parents' uncertainties, locus of control, and functional uses of mobile devices in families.

Ann Fam Med 2016;14:503-508. doi: 10.1370/afm.1976.

\section{INTRODUCTION}

S martphones, tablets, and other mobile technologies are ubiquitous in children's lives, ${ }^{1-3}$ yet these technologies have received relatively little study as a growing source of screen time. Current American Academy of Pediatrics' policy guidelines on healthy media consumption practices $^{4}$ are largely based on research examining television (TV) and video viewing, ${ }^{5}$ which differ in fundamental ways from mobile device use. Mobile devices are portable, used for a multitude of evolving purposes, and tend to be used individually. ${ }^{2}$ Although mobile technologies certainly can be used in beneficial ways, parents have frequently voiced uncertainties about whether and how best to adopt these technologies. ${ }^{6}$

Because research always lags behind adoption, individual and societal tensions that arise with the adoption of new technologies ${ }^{7}$ can seldom be resolved based on evidence for, or against, the healthfulness of a certain media usage. It is therefore crucial to understand how parents perceive the changes imposed by novel technologies upon their children's development, their own parenting experiences, family relationships, and larger culture so that physicians may offer flexible, relevant guidance in a timely 
manner. Mobile device usage by young children, even among those from disadvantaged backgrounds, ${ }^{8}$ continues to increase rapidly, and it is unclear how clinicians should intervene.

Using semistructured interviews, we explored the explanations and conceptual frameworks that caregivers hold about mobile technology use and its effects on the learning and behavior of their children. Our aims were to describe dominant themes around parents' beliefs regarding the benefits and risks of young children's mobile technology use, and then to distill these findings into actionable ideas for physicians to use when discussing digital devices with families.

\section{METHODS}

\section{Study Design}

We used a qualitative approach to analyze narrative data collected from interviews with caregivers of young children. Qualitative research is an important technique to identify diverse perspectives about social phenomena and their meaning ${ }^{9}$ and to generate relevant hypotheses on which to base further work. ${ }^{10}$ The study was approved by the Boston University Medical Center Institutional Review Board.

\section{Participants and Recruitment}

We recruited English-speaking caregivers of young children to participate in individual or small-group (2 to 5 participants) semistructured interviews. As recommended for qualitative studies, ${ }^{6}$ we used a purposive sampling frame, choosing recruitment sites that would yield a sample of parents with diverse backgrounds: an urban primary care practice, a local university, suburban parenting groups, and a digital technology company. We posted flyers advertising the study at each recruitment site and recruited a convenience sample from the caregivers who contacted our study team. We also recruited through referrals from other participants (a qualitative research technique termed snowballing ${ }^{6}$ to increase sampling of diverse viewpoints. Eligibility criteria included being the parent or legal guardian of a child aged 0 to 8 years. Informed consent was obtained before interviews commenced.

\section{Interview Structure}

Investigators (J.S.R., G.B., and J.G.) performed the semistructured in-depth interviews initially with small groups, as this approach is useful for capturing interpersonal dynamics regarding novel cultural phenomena. ${ }^{6}$ When it became apparent from focus groups that participants had much to say about their personal experiences, we began to conduct individual interviews with subsequent participants to probe more deeply into media use patterns and dynamics within families. We used an open-ended interviewing structure to elicit caregivers' perceptions of mobile device use by children, the perceived benefits and concerns, and household media rules (interview guide, Supplemental Appendix, http://www.annfammed.org/ content/14/6/503/suppl/DC1). Participants completed a brief demographic questionnaire after the interviews.

\section{Analysis}

Interviews were audiotaped, transcribed, and analyzed for themes by a group of 4 investigators from different backgrounds (developmental behavioral pediatrics, medicine-pediatrics, psychology, and health services research). Our analysis used a grounded theory approach ${ }^{6}$ investigators read each transcript looking for recurring themes or ideas that naturally arose from the text rather than imposing an existing theoretical framework onto the data. Investigators independently coded each transcript using Dedoose software (SocioCultural Research Consultants, LLC), then met to compare codes and determine required further exploration in subsequent interviews. Disagreements about themes were resolved by discussion with an investigator not involved in initial transcript analysis. Data collection and analysis continued until thematic saturation was achieved. To ensure data validity, key findings were then triangulated through meetings with experts in the field (child development experts, health services researchers, technology researchers, and primary care clinicians) and reviewed with a subset of participants. ${ }^{6}$

\section{RESULTS}

We recruited 35 caregivers (22 mothers, 9 fathers, and 4 grandmothers), of which $31.4 \%$ were single parents, $42.9 \%$ were of nonwhite race/ethnicity, and $40.0 \%$ had completed high school or less (Table 1).

Participants consistently described child mobile technology use by invoking internal tensions between competing viewpoints. Such tensions involved 3 issues: (1) effects on the child-fear of missing out on the benefits of mobile devices vs concerns about its effects on child thinking and behavior; (2) locus of controlwanting to use mobile technology in educational ways, but often feeling that rapidly evolving technologies are beyond their control (a tension more strongly expressed among lower-income families); and (3) family stress-the necessity of mobile device use in stressed families vs its displacement of family time.

\section{Tension 1: Effects on the Child}

Caregivers expressed feeling a need to introduce their child to mobile technology at an early age so that the 
child could keep up with trends in education, social connection, and employment opportunities, even if they preferred to maintain a relatively low-tech household.

The only reason we've ever introduced it is because we fear that it's going to be a primary learning device in the future.... As a parent, you never want to go ahead and put your son or daughter at any disadvantage in a group setting (Participant 6A, father, digital technology company).

Caregivers also expressed the belief that their young child could learn better from educational applications than from hands-on toys, because the child was more motivated to use such an application, the fine motor skills involved in using a touchscreen are easier, or the child felt more independence in finding and downloading the application. Despite knowing screen time limits, many caregivers felt comfortable letting their child use applications with so-called educational labels, hoping this play would translate into improved developmental skills.

I think it's good because of the motor skills. It's good for her eye coordination, and it's good for her voice, her language skills. And she's very motivated and she's content, and it keeps them content for a while.... And sometimes writing

\section{Table 1. Characteristics of Study Participants, $\mathrm{N}=35$}

\begin{tabular}{lc}
\hline Characteristic & Value \\
\hline Age, mean (SD), Y & $35.8(23-55)$ \\
Race/ethnicity, No. (\%) & \\
White (non-Latino/Hispanic) & $20(57.1)$ \\
Black (non-Latino/Hispanic) & $10(28.6)$ \\
Latino/Hispanic & $2(5.7)$ \\
Other & $3(8.6)$ \\
Single parent, No. (\%) & $11(31.4)$ \\
Educational attainment, No, (\%) & $14(40.0)$ \\
High school, GED, or less & $4(11.4)$ \\
Associate's degree or some college & $5(14.3)$ \\
Bachelor's degree & $10(28.6)$ \\
Graduate or professional school & \\
Occupational status, No. (\%) & $11(31.4)$ \\
Full-time employment & $10(28.6)$ \\
Part-time employment & $12(24.3)$ \\
Homemaker or looking for work & \\
Relationship to child, No. (\%) & $22(62.9)$ \\
Mother & $9(25.7)$ \\
Father & $4(11.4)$ \\
Grandmother & $16(45.7)$ \\
Age of child, No. (\%) & $16(45.7)$ \\
0-2 y & $22(62.9)$ \\
3-5 y & \\
6-8 y & \\
\hline GED = general equivalency diploma. & \\
\hline
\end{tabular}

and stuff like that, and coloring-it gets to be boring to them (Participant 4A, mother, urban clinic).

When questioned, no caregiver identified specific resources to find high-quality educational applications; they usually used the application store as a guide, or let the children find the application themselves.

When voicing uncertainty about mobile technology use in early childhood, caregivers often expressed concern that with time such use would affect the way the child thinks or behaves. Concerns included lower creativity, critical thinking, persistence, social skills, and real-world problem-solving, or a tendency for the child to prefer passive consumption or digital play to other activities.

My main concern is how some of these devices tend to make at least my 7-year-old a bit more dependent on stimuli that he does less critical or imaginative problem solving as a result. The device can do it for me. It can feed my eyes, and I don't need to think around problems. The technology will do it for me (Participant 13A, father, academic institution).

In addition, caregivers who endorsed a family history of addiction worried about how attached a child was becoming to mobile devices or video games. They relayed stories of children-usually boys—thinking about the games throughout the school day, having dreams about the games, and feeling the need for their children to "go cold turkey" around mobile device so that they would go back to playing with traditional toys and games.

I feel like [my son] is more, like, attached to, you know, these, just the games and stuff. Like, he doesn't—like, we'll go somewhere, and he'll be, like, "I want to stay and play the video game," ... and that's all he cares about, honestly (Participant $5 \mathrm{~A}$, mother, urban clinic).

Despite this concern, mobile device was also cited as a way to teach children how to calm themselves down:

I think just playing the games and learning that she's-you have to wait this long to level up and you can't always buy the extras to it. I think to a certain extent, it's teaching her patience. And then it's also teaching her to be calm (Participant $2 \mathrm{~A}$, grandmother, urban clinic).

\section{Tension 2: Locus of Control}

Lack of the parent's self-efficacy or perceived control around setting limits was a frequently cited consequence of children's mobile technology use, particularly by caregivers recruited from the urban clinic. Despite wanting to use mobile devices to help their children learn, these caregivers described not knowing how to keep up with the rapidly evolving media landscape, including how to choose good educational applications 
or safe websites. In contrast to the comfort most parents expressed with hands-on learning activities, such as reading, play, or crafts (eg, "[Reading to her] helps me out. It helps me feel like a better person, too, you know? I'm doing something."-Participant $1 \mathrm{~A}$, mother, urban clinic), technology use was described as unfamiliar territory, where children knew better than parents how to navigate it. "I used to take my son's phone, I used to take his game. You know what, they always found a way to play it" (Participant 4A, mother, urban clinic).

Other sources of lack of control involved the unregulated nature of the Internet, the ease with which children can download applications without help, and the influence of older siblings. Caregivers recruited from the urban clinic expressed a hope that limitsetting capabilities could be embedded in the device itself; others gave examples of letting their child use only those devices (eg, LeapPads) with no Internet access, or letting them use the device only when the battery was about to run out to avoid the tantrums that might come when the device is taken away.

This concern was contrasted with caregivers from higher socioeconomic strata, who described a higher sense of comfort around technology and gave examples of ways they use media to enrich their parenting experience. For example, they discussed having far-away relatives read their child a bedtime story via videophone applications, or using devices or applications creatively:

My daughter will borrow my phone and take pictures of her world as she sees them. And I love it. I will come back to my phone sometimes and be scrolling through the photos, and there will be 30 in a row of her feet... And sometimes it's on accident. But I'll ask her, and sometimes it's on purpose.

...but it's like my view into how she sees the world, and I love that (Participant 13B, mother, academic institution).

\section{Tension 3: Family Stress}

Caregivers echoed each other's amazement at how well mobile devices kept their children quiet. This effect was noted as a help during church or music recitals, on long days indoors when there were few other play options, or to calm a child after a behavioral incident.

Just, it's so easy to put your feet up.... Just plug it in and it's over with... and he's watching a DVD and I'm on my phone... It's quiet and peaceful.... It's like no conflict (Participant 7A, mother, urban clinic).

Compared with television, applications and games were described as providing a range of safe, free activities that give immediate positive feedback to the child, which caregivers saw as both pride-building as well as potentially addicting, ie, because other real-life activities are not giving the child the same sense of mastery.
He's incredibly competitive. So I guess some of my concerns about that are that he's using the gaming time to not have to worry about the stresses of competition per se. And that he's missing out on some opportunities to learn strategies for dealing with competition, because he's a sore loser at times.... So I guess that we try to limit the amount of time he's passively, vicariously winning [on video games] (Participant $13 \mathrm{~A}$, father, academic institution).

Homeless or lower income caregivers described feeling that they were being a good parent by providing their child with a device now popularly recognized as an educational resource. Because toys are expensive and easily broken, families with fewer financial means appreciated being able to let their child download free applications.

Sometimes what if you're broke or something, and you can't have fun with them all the time, and you have to stay in the house, and you have to read books all day, you have to entertain them at home, you know what I mean...? When we're broke, they're nagging me, and now I feel bad because we don't have nothing to do. So I let her be in her phone (Participant 3B, mother, urban clinic).

It should be noted, however, that other caregivers expressed having difficulty affording tablets, wireless Internet, or other mobile devices, and they either rented them or would forego other necessities (eg, clothing) to purchase mobile devices or gaming consoles.

Despite these perceived benefits, some families described not recognizing how much family time was being displaced by mobile device use until they no longer had access to it:

We had the hurricane last year, and we lost power...we made cupcakes before the power went out. When the power went out we put the candles on, and we played a game, we were together, it was the best day we ever had because there was no TV going, there was no computer going, there were no phones going (Participant 1C, mother, urban clinic).

This realization resulted in ambivalence or internal tension that interfered with parents confidently making a coherent set of rules for technology use:

Like, I don't want to see him use it for any longer than 30 minutes... he looks like a zombie and I hate that, and I feel guilty. I am guilty, so-but it works (Participant 7B, mother, urban clinic).

Because of these internal tensions, caregivers expressed wanting to talk about mobile technology with trusted clinicians, keeping the child's best interest at the center of the discussion so they do not feel judged.

I think that should be discussed much younger too. I got pamphlets on my child's vaccines, but I've never been 
addressed about mobile devices at age 1 year...the pediatrician should actually be doing it sooner just so that parents could actually know, because those rules are actually really good (Participant 1A, mother, urban clinic).

\section{DISCUSSION}

Based on the tensions that caregivers feel about these novel mobile technologies, our data suggest that several new dimensions might be added to discussions about their use in early childhood. A diverse sample of mothers, fathers, and grandmothers reported feeling much uncertainty about whether mobile devices are beneficial or harmful to their children's development, how to use mobile devices beneficially when its rapid evolution seems out of their control, and the important functional purposes media serves in their families despite displacing family time. Such cognitive dissonance or ambivalence presents prime opportunities for influencing behavior change ${ }^{11,12}$; exploring inherent tensions in the unknowns surrounding emerging technologies may therefore be an effective entry point into clinicians' conversations with parents.

A primary tension expressed by caregivers was uncertainty about whether allowing young children to use mobile devices would benefit or harm their development. Fears about negative effects on the children's critical thinking, imagination, and social skills were contrasted with hopes that interactive technology could be more educational. This uncertainty may be an opportunity for clinicians to use the existing evidence base about mobile devices to correct parents' misperceptions and make suggestions for healthy media use. For example, it is important to address misperceptions that children younger than 2 years can learn words, fine motor skills, or such higher order skills as patience from screen media when evidence strongly suggests they cannot, at least without the help of an adult. ${ }^{13}$ There was also a strong belief among low-income parents in marketing claims that commercially available applications are educational ${ }_{i}$ yet, several reviews of children's educational applications have shown they are generally of poor quality, target rote skills, and have no evidence base. ${ }^{14,15}$

It can be difficult to address the negative aspects of mobile technology use when parents are proud of themselves for providing educational opportunities for their young children. Recent studies show, however, that the earlier the mobile device is introduced in early childhood, the worse the child's attentional and cognitive outcomes may be. ${ }^{16}$ Instead, clinicians can remind parents that they are their child's best teacher, and the best application cannot parallel the developmental benefits of hands-on, unstructured, face-to-face, or outdoors play. ${ }^{17}$ When children do learn new things from applications or educational programming, parents should help their child apply this new knowledge to the 3 -dimensional world around them ${ }^{14,18}$ by exploring the new concept through play or conversation, rather than allowing the prolonged play that can result from games or videos automatically advancing.

Finally, clinicians can encourage parents to teach their children not only the technical aspects of device use, such as tapping or swiping, but also teach and model digital literacy: how to think about using digital devices as a socially constructed tool to connect, create, and build knowledge..$^{19}$ For example, if parents show a child how to use a tablet's camera to take photos and create stories, the child will likely see tablets as a creative tool, rather than only serving entertainment ${ }^{3}$ or soothing purposes. ${ }^{20}$

Caregiver locus of control was also a strong overarching theme, one that tracked strongly with socioeconomic status. Although more technologically savvy parents expressed feeling comfortable creating rules around digital device use in early childhood, many caregivers recruited from an urban clinic described their empowerment being worn away by the unlimited expanse of an unregulated Internet, their child's demands for this preferred activity, peer influences, and not knowing what the child was downloading. It was thus evident that socioeconomic disparities strongly shaped caregivers' perspectives on technology $y_{i}$ low-income caregivers wanted their children to be exposed to all of technology's promise but felt unsure how to handle its perils. Many caregivers voiced wanting their child's pediatric clinician to be a nonjudgmental partner in proactively creating rules about mobile technology use, providing resources to determine which applications and technologies are beneficial and which to avoid, and giving them the tools to monitor their child's increasingly complicated and immersive experience with digital devices from an early age. Clinicians can respond to this digital divide in parent knowledge by empowering parents to use good online resources (eg, HealthyChildren. org provides a Family Media Use Plan template and instructions; ${ }_{\text {; }}$ Common Sense Media rates applications and provides tips for caregivers).

Another dominant theme in our data was how parents use technology in dealing with the stress of their daily lives. Caregivers discussed novel conceptualizations of digital devices as a vehicle for quiet and conflict avoidance, of devices as a status symbol or sign of good parenting, and of applications as free ways to entertain, educate, and build a sense of mastery in their young children. With these powerful parenting motivations driving device use, it is improbable that one-size- 
fits-all guidance will be heeded or effective. To effect mobile technology use behavior change, clinicians will have to offer replacement solutions that suit the same ultimate purpose.

Although our study sampled a diverse population to obtain a variety of views on this novel topic, it was limited by its sampling from distinct organizations, which may have limited the scope of perspectives we analyzed. Based on the sample size, we were not able to use mixed-methods approaches to explore whether parents' perspectives varied by such characteristics as sex or age. The strength of these interviews, however, is that they provide a description of the psychosocial context in which digital media-developed in idealized laboratories and board rooms-is actually used in the daily lives of American families.

We propose a framework with which pediatric clinicians can respectfully and realistically discuss evolving behaviors regarding mobile technology use so that caregivers can make informed and empowered decisions. Specifically, clinicians can elicit (1) parents' hopes and fears of what effect these technologies may have on their children, then correct any misperceptions, and discuss evidence of risks and learning potential ${ }_{i}(2)$ parents' level of confidence in choosing content, monitoring usage, and setting time limits for children, then empower parents with appropriate tools or resources; and (3) parents' understanding that mobile devices may be serving important functions for stressed families, such as maintaining a peaceful household or providing educational opportunities, then help parents address these functions in other ways if changes in mobile device use are recommended. Through such conversations, clinicians can support parents in making proactive plans for how they want mobile technology to be used in their households.

To read or post commentaries in response to this article, see it online at http://www.annfammed.org/content/14/6/503.

Key words: parenting; media; child development

Submitted November 14, 2015; submitted, revised, May 30, 2016; accepted June 14, 2016.

Funding support: This research was funded by an Academic Pediatric Association Bright Futures Young Investigator Award (J.S.R.).

Previous Presentation: Pediatric Academic Societies Poster Symposium; April 25-28, 2015; San Diego, California.

Acknowledgments: The authors would like to thank Dr Judith Shaw for her thoughtful guidance on this research proposal.

Supplemental materials: Available at http://www.annfammed. org/content/14/6/503/suppl/DC1.

\section{References}

1. Smith A, Pew Internet and American Life Project. US Smartphone Use in 2015. Pew Research Center. http://www.pewinternet. org/2015/04/01/us-smartphone-use-in-2015/. Published Apr 1, 2015. Accessed Oct 28, 2015.

2. Wartella E, Rideout V, Lauricella AR, Connell SL. Parenting in the age of digital technology: a national survey. http://familieslearning. org/pdf/ParentingAgeDigitalTechnology.pdf. Updated Jun 2014. Accessed Oct 28, 2015.

3. Vaala SE, Bleakley $A$, Jordan AB. The media environments and television-viewing diets of infants and toddlers: findings from a national survey of parents. Zero Three. 2013;33(4):18-23.

4. Brown A; Council on Communications and Media. Media use by children younger than 2 years. Pediatrics. 2011;128(5):1040-1045.

5. Alper M, Katz VS, Schofield-Clark L. Researching children, intersectionality, and diversity in the digital age. J Children Media. 2016; 10(1):107-114.

6. Livingstone S, Mascheroni G, Dreier M, Chaudron S, Lagae K. How parents of young children manage digital devices at home: The role of income, education, and parental style. London, England: EU Kids Online, LSE; 2015.

7. Ling R. The mobile connection: the cell phone's impact on society. San Fransisco, CA: Morgan Kaufman Publishers; 2004.

8. Kabali HK, Irigoyen MM, Nunez-Davis R, et al. Exposure and use of mobile media devices by young children. Pediatrics. 2015;136(6): 1044-1050.

9. Giacomini MK, Cook DJ. Users guide to the medical literature: XXIII. Qualitative research in health care A. Are the results of the study valid? JAMA. 2000;284(3):357-362.

10. Co JP, Perrin JM. Qualitative research and ambulatory pediatrics. Ambul Pediatr. 2005;5(3):129-130.

11. Williams $A A$, Wright $K S$. Engaging families through motivational interviewing. Pediatr Clin North Am. 2014;61(5):907-921.

12. Freijy $T$, Kothe EJ. Dissonance-based interventions for health behaviour change: a systematic review. Br J Health Psychol. 2013;18(2): 310-337.

13. Radesky JS, Schumacher J, Zuckerman B. Mobile and interactive media use by young children: the good, the bad, and the unknown. Pediatrics. 2015;135(1):1-3.

14. Hirsh-Pasek K, Zosh JM, Golinkoff RM, Gray JH, Robb MB, Kaufman J. Putting education in "educational" apps: lessons from the science of learning. Psychol Sci Public Interest. 2015;16(1):3-34.

15. Guernsey L, Levine M. Tap Click Read. New York: Wiley: Jossey-Bass; 2015.

16. Nathanson Al, Aladé F, Sharp ML, Rasmussen EE, Christy K. The relation between television exposure and executive function among preschoolers. Dev Psychol. 2014;50(5):1497-1506.

17. Ginsburg KR; American Academy of Pediatrics Committee on Communications; American Academy of Pediatrics Committee on Psychosocial Aspects of Child and Family Health. The importance of play in promoting healthy child development and maintaining strong parent-child bonds. Pediatrics. 2007;119(1):182-191.

18. Lerner C, Barr R. Screen Sense: Setting the Record Straight. ResearchBased Guidelines for Screen Use for Children Under 3 Years Old. Washington, DC: Zero To Three; 2014

19. Rogow F. Media Literacy in Early Childhood Education: InquiryBased Technology Integration. In Chip Dohohue, ed, Technology and Digital Media in the Early Years: Tools for Teaching and Learning. Washington, DC: National Association for the Education of Young Children; 2014.

20. Radesky JS, Peacock-Chambers E, Zuckerman B, Silverstein M. Use of Mobile Technology to Calm Upset Children: Associations With Social-Emotional Development. JAMA Pediatr. 2016;170(4):397-399. 